\title{
Coconstrução da autonomia do cuidado da pessoa com diabetes
}

Rosilei Teresinha Weiss Baade(a)

Edison Bueno ${ }^{(b)}$

Baade RTW, Bueno E. Co-constyruction of the healthcare autonomy for person with diabetes. Interface (Botucatu). 2016; 20(59):941-51.

This is a qualitative research on the coconstruction of the autonomy of care for individuals with diabetes through the reflections of diabetic users and health professionals in a team of a specialized public clinic, located in a medium-sized municipality in southern Brazil. Data were collected through semi-structured interviews of people with diabetes, health professionals and a conversation meeting with professionals about the discourses of these users. The analysis was guided by content analysis, specifically thematic analysis. Listening, expanded clinical approach and co-management proved to be key strategies to understand and live and copel with diabetes as a singular process by creating strategies shared between disease bearers and health professionals, where the disease is part of life, not life part of the disease

Keywords: Co-construction. Diabetes mellitus. Autonomy. Care. Expanded care.
Trata-se de uma pesquisa qualitativa sobre a coconstrução da autonomia do cuidado da pessoa com diabetes, por meio das reflexões dos usuários diabéticos e profissionais de saúde de uma equipe de ambulatório especializado público, localizado num município de médio porte no sul do Brasil. Os dados foram coletados por intermédio de entrevistas semiestruturadas de pessoas com diabetes, profissionais de saúde e uma Roda de Conversa com os profissionais sobre as falas destes usuários. Os dados obtidos foram submetidos à análise de conteúdo, especificamente, a análise temática. A escuta, a clínica ampliada e a cogestão se afirmaram como estratégias potentes para compreender o viver e o lidar com diabetes como um processo singular e compartilhado entre adoecidos e profissionais de saúde, onde a doença faça parte da vida e não a vida parte da doença.

Palavras-chave: Coconstrução. Diabetes mellitus. Autonomia. Cuidado. Clínica ampliada.

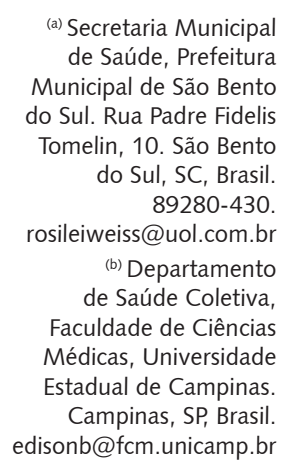

(a) Secretaria Municipal de Saúde, Prefeitura Municipal de São Bento do Sul. Rua Padre Fidelis Tomelin, 10. São Bento do Sul, SC, Brasil. 89280-430.

rosileiweiss@uol.com.br

(b) Departamento de Saúde Coletiva, Faculdade de Ciências Médicas, Universidade Estadual de Campinas.

Campinas, SP, Brasil. edisonb@fcm.unicamp.br 


\section{Introdução}

A prevalência de doenças crônicas não transmissíveis tem aumentado no mundo todo e no Brasil. Segundo o Ministério da Saúde ${ }^{1}$, a prevalência de diabetes apresenta um crescimento contínuo, com 5,5\% em 2006 e 6,9\% em 2013, com elevação conforme a idade, atingindo mais de $20 \%$ das pessoas acima de 65 anos. A Federação Internacional de Diabetes (IDF) ${ }^{2}$ estima prevalência de diabetes em $6,5 \%$ da população de vinte a 79 anos.

A diabetes mellitus (DM) ${ }^{3}$ faz parte de um grupo heterogêneo de distúrbios metabólicos que apresentam em comum a hiperglicemia, resultante da alteração da ação ou da excreção da insulina pelo pâncreas de forma parcial ou total, que irão classificar os tipos de diabetes, de acordo com a sua etiologia, em: DM 1, DM 2, diabetes gestacional e outros tipos específicos. Também há duas categorias classificadas como pré-diabetes: a glicemia de jejum alterada e a intolerância à glicose.

As complicações relacionadas à DM podem ser agudas, como a hipoglicemia e a hiperglicemia; e crônicas, como alterações microvasculares, macrovasculares e neuropáticas ${ }^{4}$, o que gera impacto direto na qualidade de vida da pessoa com diabetes. O tratamento é voltado para a manutenção das taxas glicêmicas ${ }^{3,5}$ o mais próximo dos padrões de normalidade estabelecidos, por meio da associação de medicamentos orais e/ou insulinas, automonitoramento glicêmico, adequação da alimentação e atividades físicas regulares. Podem variar conforme o caso clínico, mas caracterizam o enfoque dado pelos profissionais de saúde na formulação do plano terapêutico.

No atendimento diário, percebe-se a singularidade da adaptação dos usuários após o diagnóstico de diabetes, pelo contexto adverso e controlador da mudança em sua vida, com cuidados relacionados à patologia, contato com serviços de saúde, variabilidade da doença e mudança da necessidade de cuidado ao longo do tempo.

É inegável que os avanços científicos levaram à melhoria do manejo da DM ao longo dos anos, desde a descoberta da insulina, com avanços tecnológicos em relação a dispositivos de aplicação, monitoramento e tempo de ação dos medicamentos, contribuindo, inclusive, para o aumento da expectativa de vida dos diabéticos.

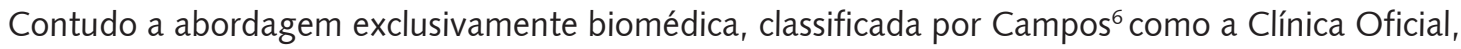
hegemônica na maioria dos serviços de saúde brasileiros, tem conduzido a práticas com um enfoque muito prescritivo da adesão ou não ao tratamento. Cabendo ao adoecido, com frequência, seguir o que está sendo instituído, sem espaço para dialogar e pactuar, com o profissional à sua frente, um plano terapêutico que seja significativo para sua vida, aprendendo a lidar e conviver com a diabetes.

Na proposta de $\mathrm{Campos}^{6}$, não se trata de achar um método que a substitua, e sim enfrentar os nós críticos da Clínica Oficial para poder reformulá-la, tornando-a uma Clínica Ampliada, inserindo novos modos de saber-fazer e com relações mais democráticas entre os profissionais de saúde e os usuários, entre os próprios profissionais de saúde e, também, com a gestão. É essencial enxergar o outro como sujeito, não de um modo simplificado, mas de uma maneira em que a singularidade dos sujeitos possibilite a criação de arranjos mais potentes na busca da integralidade do cuidado.

O conceito de sujeito ${ }^{6-9}$ pode ser definido como o ser que conhece, multifacetado, singular, com potencial espírito crítico e protagonista de sua própria existência. Campos ${ }^{6}$ reforça a influência do meio e da capacidade de o sujeito modificar sua realidade "mediante processos de análise e de intervenção sobre estes fatores" (p. 25), podendo estar inseridos nos planos conscientes ou inconscientes, vinculados ao "plano biológico, de desejos, interesses, necessidades sociais e das instituições" (p. 49) por onde este sujeito transita.

A subjetividade ${ }^{10-12}$ presente na relação com o outro, refere-se à maneira pela qual os indivíduos conseguem dar vazão, expressar estes planos, podendo ser entendida como o mundo interno dos seres humanos, compreendendo: seu modo de pensar, os significados, emoções e sentimentos, a influência da sua trajetória e do meio em que está inserido.

Campos $^{6}$ define singularidade como "os modos de ser e de agir, bem como os de construir, tudo misturado, onde o sujeito vive imerso e ele é em função destes planos sobre ele e ele se singulariza interferindo nestes planos" (p. 50). 
Em relação à clínica, entende-se que o modelo hegemônico privilegia o controle sobre os pacientes, desconsiderando sua subjetividade, singularidade e crenças em relação à doença, passando a considerar apenas os aspectos objetivos de suas falas, para obter o diagnóstico da doença e estabelecer a terapêutica ${ }^{6,13 .}$

Além de Campos ${ }^{6,14}$, as propostas de Cecílio ${ }^{15} \mathrm{em}$ relação às dimensões do cuidado e de Merhy ${ }^{16}$, com o trabalho vivo em ato tornam necessário repensar as práticas instituídas, em especial, nas doenças crônicas, que geram a necessidade de cuidados longitudinais. A doença crônica pode ser definida como um conceito biomédico utilizado para designar problemas de saúde incuráveis ou de longa duração, responsável por colocar limites orgânicos para o indivíduo doente e técnicos para os profissionais de saúde ${ }^{17}$.

Ao considerar os aspectos de representação social na construção do conceito de doença, Palmeira ${ }^{18}$ afirma que ela é "compreendida e relatada pelos diversos atores sociais em contextos diferentes, tornando-se importante destacar que há diferenças entre o processo biológico da doença, a compreensão e sensações individuais deste itinerário e a construção social desta situação de saúde" (p. 99).

No processo de produção de autonomia nos coletivos e nos indivíduos, analisando o conceito em sua interface com a saúde coletiva ${ }^{9,19,20}$ e a subjetividade, observa-se que é vinculado a capacidade dos sujeitos "de apropriação pela reflexividade"9 (p. 835), pela experiência e "capacidade de transformá-la a partir de projetos coletivos, construídos eticamente com outros

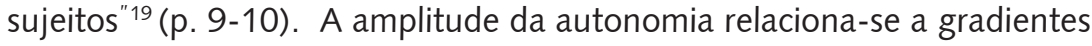
passíveis de terem seus limites tensionados, pois, como vivemos em um coletivo, sempre haverá um grau de dependência em relação a 'algo ou alguém'20. Assumse, para a realização deste trabalho, o conceito proposto por Campos e Onocko Campos $^{20}$ :

[...] entendemos autonomia como a capacidade do sujeito de lidar com a sua rede de dependências. [...] um processo de coconstituição de maior capacidade dos sujeitos de compreenderem e agirem sobre si mesmos e sobre o contexto conforme objetivos democraticamente estabelecidos. (p. 720)

A coconstrução, como abordagem na área da pedagogia e sua interface com a saúde coletiva, procura integrar elementos cognitivos e sociais ${ }^{21}$ nos processos de interação entre indivíduos e/ou grupos. Na saúde coletiva, a coconstrução assume a conotação de trabalho conjunto, construído com o outro, podendo ser este outro a pessoa ou o usuário em busca de atendimento; com o outro colega profissional da saúde; com a equipe de saúde; com a gestão local, que pode ter como objetivo o cuidado.

Para Campos e Onocko Campos ${ }^{20}$, a coconstrução de autonomia, além de produzir saúde, deve coproduzir sujeitos. Assim, é fundamental que os profissionais de saúde, neste processo, sejam considerados como sujeitos singulares e possam produzir ações de saúde que sejam significativas para eles, conforme Campos ${ }^{6}$, produzindo de modo simultâneo à coprodução de sujeitos (agente da produção) e do coletivo organizado (equipe de saúde), tudo junto e misturado, produzindo valores de uso ${ }^{(c)}$ para as pessoas que procuram o serviço, por meio da clínica ampliada e compartilhada, reforçando o papel de sujeitos e, com isto, articulando o próprio sujeito (profissional) com o usuário e com o Coletivo Organizado (a equipe de trabalho), para se coproduzir permanentemente, acreditando na formação integral do ser humano ${ }^{14}$. 
Neste contexto, a coconstrução da autonomia do cuidado em diabetes se desenha considerando a subjetividade do sujeito em lidar e conviver com a doença como um processo singular, onde o profissional de saúde desempenha um papel de intermediação entre o conhecimento científico e as necessidades daquele sujeito, na construção de um plano terapêutico significativo dentro do projeto de vida do outro, tanto para o adoecido, como significativo para o profissional e a equipe.

\section{Trajetória metodológica}

Trata-se de uma pesquisa qualitativa, realizada num ambulatório público especializado de São Bento do Sul - SC. Foi constituída amostra intencional de oito pessoas com diabetes que utilizavam este serviço e cinco profissionais de saúde que faziam parte da equipe de atendimento.

Os critérios de inclusão no estudo para as pessoas com diabetes foram: ter condições físicas, emocionais ou cognitivas de compreensão das questões elencadas, utilizar insulina e automonitoramento glicêmico diariamente; ter perfis diferentes em relação ao tipo de diabetes, idade, sexo, perfil de controle, tempo de diagnóstico e ter ou não complicações crônicas. Com relação aos profissionais de saúde, todos os profissionais foram convidados a participar. Apenas uma não quis participar e a outra estava desenvolvendo este estudo.

A coleta de dados ocorreu entre abril e novembro de 2014, sendo realizada pela pesquisadora, para o desenvolvimento da dissertação de conclusão do Mestrado Profissional em Saúde Coletiva, Gestão e Políticas Públicas, da Unicamp. A seleção dos participantes ocorreu durante o desenvolvimento das atividades no referido ambulatório, com o convite para pessoas com diabetes com o perfil desejado e para os profissionais que atuavam no serviço. Foram realizadas entrevistas semiestruturadas, com a gravação das interações, em ambiente reservado. Após a transcrição e análise inicial das falas das pessoas com diabetes, foi realizada uma Roda de Conversa ${ }^{6}$ com os profissionais de saúde, a respeito das percepções que a equipe tinha em relação às falas.

Os roteiros das entrevistas foram distintos para profissionais e pessoas com diabetes, destacando-se o intuito de compreender o significado de temas semelhantes para estes públicos específicos, por meio de falas sobre: o adoecimento, o viver com diabetes, o lidar com os diversos dispositivos terapêuticos relacionados a esta patologia, a autonomia do cuidado, as inter-relações entre as pessoas envolvidas neste processo e a importância da educação em saúde.

Dentro das abordagens das pesquisas qualitativas, optou-se pela análise de conteúdo, em especial, a análise temática proposta por Minayo ${ }^{22}$, com referenciais de Bardin e outros autores na apreciação dos dados.

A discussão dos resultados foi realizada por intermédio da análise das informações obtidas pelas entrevistas semiestruturadas com as pessoas com diabetes, com os profissionais de saúde e das percepções vinculadas à roda de conversa sobre as falas dos adoecidos.

\section{Resultados}

Para entender o processo de adoecimento, a escuta da narrativa de cada sujeito sobre a sua experiência de vida e a interface com o adoecimento, tem como objetivo explicitar esta singularidade, apoiando o desenvolvimento da autonomia e ressignificando aspectos da vida.

Neste contexto, as falas remetem a uma situação de ruptura entre o conhecido e a normalidade, a possibilidade de viver sem limites seus desejos e vontades, em relação à comida, bebida e convívio social, para uma situação de estranhamento, insegurança, pensamentos sobre a imposição de limites e limitações na vida, isolamento social, perceber ou não os sinais físicos da doença, a dificuldade de aceitação e convívio com esta mudança.

O sofrimento psíquico relatado acentua-se na fase de diagnóstico e ao vivenciar as complicações da doença. O tempo de adaptação decorrente da imposição das mudanças mostrou-se muito variável, desde algumas horas até vários anos, mobilizando recursos internos e externos para o seu enfrentamento. 
Neste sentido, entende-se como significativos os estudos relacionados ao grau de resiliência 23,24 maior em pessoas que enfrentam de uma forma construtiva a doença, as mudanças decorrentes dela e a classificação de estágios psicológicos relacionados à adaptação para a mudança ${ }^{25}$.

Independente das estratégias utilizadas, o primordial é manter a percepção sobre a conexão entre a doença e a vida do sujeito. Este processo poderá variar ao longo do tempo, entendendo que a singularidade dele é essencial para definir as possibilidades de cuidado, não com modelos fechados a serem instituídos, e sim como possibilidades de construção.

A empatia, para os profissionais de saúde, surgiu trabalhando com esta realidade, partilhando práticas com outros profissionais, experiências pessoais ou de familiares com o diagnóstico e de vivenciar a diabetes gestacional. Mas o reconhecimento do sofrimento gerado pelo adoecimento ainda é incipiente em suas falas, reproduzindo o enfoque biomédico com maior ênfase. Reforçam os cuidados relacionados ao corpo físico, a disposição para mudança, os hábitos de vida e a avaliação quantitativa de indicadores.

As dificuldades de conviver com a diabetes referem-se às medidas terapêuticas, como a realização do automonitoramento e a adaptação à rotina exigida, vinculada às demandas da vida. Um dos profissionais também resolveu experimentar o automonitoramento e aplicação de insulinas para criar a sua percepção de dor em relação aos procedimentos.

No decorrer das falas, surgem outras percepções sobre o adoecimento e seus desdobramentos, como: a ruptura do conhecido e o restabelecimento da normalidade, a necessidade de adaptação a novos conhecimentos e habilidades, o medo da doença e da morte, refletindo a singularidade do sujeito e a intersubjetividade presente.

Quando as pessoas com diabetes foram instigadas a relatar os desafios de viver e lidar com esta doença, o intuito era verificar o impacto nas atividades diárias, com enfoque nas medidas terapêuticas, mas deixando a fala livre para o que julgassem pertinente.

Nestas falas, as medidas terapêuticas, como aplicação de insulina, automonitoramento, atividade física e alimentação foram citadas, sendo que algumas de modo inusitado: "a questão de aplicar a insulina e fazer o exame do dedo, isso é tranquilo", "por isso, a rotina que o diabético tem, do medicamento, de fazer os testes, isto eu achava que seria complicado, mas eu sei que foi a mais fácil de eu me adaptar". E outras falas reforçam que estes cuidados podem ser incorporados à rotina após algum tempo realizando-os.

A atividade física regular foi colocada como um desafio maior em algumas falas. Em outras, que mesmo associadas às complicações, como perda de visão, amputação e risco de hipoglicemia, foi possível aprender como manejar a situação e realizá-la.

Em diversas citações, as mudanças relacionadas à alimentação surgem como um dos principais desafios enfrentados. Referem-se à conotação de privação, restrições, reforçar o diferente quando a família não compartilha os cuidados, ou de conviver socialmente, com a transformação de alimentos como massas e pães em açúcares e o prazer associado à comida. Algumas falas dos adoecidos também apontam a alimentação como uma situação resolvida, por meio da experiência e do conhecimento adquirido, focando numa alimentação mais saudável e moderada.

Quando estas falas foram levadas à roda de conversa, geraram estranhamento por parte dos profissionais, pois não condizem com o que mais impactaria para eles em ter diabetes.

Uma das profissionais acredita que ainda ocorram muitos mitos em relação à alimentação dos diabéticos, por hábitos culturais equivocados. Entendemos que os hábitos culturais são um dos aspectos da abordagem sobre mudanças alimentares, para adequação entre o biomédico e o singular.

Os demais profissionais discutiram, empiricamente, os motivos pelos quais a alimentação teve uma expressão tão frequente nas falas dos adoecidos, como: a exigência de disciplina, privação de certos alimentos, convívio social, obtenção de prazer e exercer a função de 'válvula de escape' para o alívio de diversas angústias. Foi pontuado que, mesmo dentro do grupo dos profissionais de saúde, onde há o conhecimento dos benefícios da alimentação saudável, no momento de fazer as escolhas pessoais, optar pelo saudável e moderado não é confortável para todos.

Cyrino ${ }^{5}$ classificou em seu estudo este tema como o "mais difícil de lidar" (p. 197), em diversos campos, apontando esta "como uma das dimensões mais relevantes para o cuidado de si" (p. 197), 
em relação à $D M 2$, pois a principal dificuldade deles é "nunca mais poder comer e beber normalmente como todos os outros" (p. 196).

É importante ressaltar que o impacto na vida das pessoas em ter uma doença crônica, em geral, não é alcançado facilmente pelos profissionais de saúde, pela amplitude do contexto. Os adoecidos referiram: as mudanças impostas pelo adoecimento, por complicações agudas e crônicas, internações, mudança na vida profissional/produtiva, dependência nas atividades de vida diária, mudanças na vida sexual, sofrimento psíquico associado ao controle dos familiares, e sobrecarga de funções para a família por lidar com um membro adoecido, contar para os outros sobre ter diabetes, medo de hipoglicemias, medo da morte e a depressão.

Ocorreram falas indiretas sobre o consumo de álcool e o tabagismo, associados ao diagnóstico e tratamento da diabetes. E que a manutenção da rotina vinculada ao tratamento da diabetes é monótona, repetitiva e enfadonha, o que entendem como um dificultador para a realização do autocuidado.

Outras falas pontuam a adaptação, mas reconhecem que seria melhor não conviver com a situação de adoecimento. Também associam o tempo em que lidam com as medidas terapêuticas e o adoecimento como necessário para esta adaptação.

$\mathrm{Na}$ análise entre as falas dos profissionais com os adoecidos, elas não condizem de modo contundente sobre as maiores dificuldades que eles percebem. O que ressalta a importância de perguntar ao outro o que o afeta, pois a singularidade e a subjetividade pertencem a cada indivíduo, não competindo ao profissional de saúde inferir o significado que a situação tem para cada sujeito.

As doenças crônicas pressupõem um cuidado longitudinal que gera, para os usuários, a necessidade de manterem contato com os profissionais de saúde por um período muito longo, com frequência variável de interação e da intensidade dos cuidados.

Por outro lado, os profissionais de saúde acreditam conhecer esta clientela e instituem certo controle sobre esta população de risco. Esse controle quase sempre está centrado nas ações sobre a patologia e nas complicações de longo prazo.

Questionaram-se as pessoas com diabetes sobre sua relação com os profissionais de saúde e como tomam a decisão de seguimento ou não das propostas terapêuticas. Abordaram fatos atuais e de sua trajetória de vida. Em todas as respostas, houve referências ao atendimento médico, de diversas especialidades, sendo citados de forma pontual: o nutricionista, fisioterapeuta, cirurgião-dentista e profissionais de enfermagem.

As situações negativas na inter-relação remetem ao diagnóstico, pela falta de sensibilidade em relação ao seu sofrimento e na adesão pelo medo. Nos demais momentos, pela falta de diálogo, pouco contato com o profissional médico, percepção de ser culpabilizado pelos resultados, foco apenas nas questões biológicas e necessidade de perceber que aquele profissional à sua frente esteja realmente interessado em ajudar.

No relato de experiências positivas, a percepção pelos usuários sinaliza: acolhimento, escuta, cuidado, fluxos de afetos positivos, vínculos e relações de respeito com o outro.

Os adoecidos decidem sobre o seguimento ou não das orientações recebidas, por meio da busca de informações, autopercepção dos efeitos da doença e dos hábitos em seu organismo, crença de que a informação dada pelos profissionais os auxilia na manutenção de sua saúde, amor à vida, manutenção da convivência familiar, e aproveitar uma segunda chance de viver cuidando melhor de sua saúde.

Em algumas respostas, não houve clareza sobre o que foi questionado. Considerando a interação com a pessoa com diabetes e os dados tradicionais em relação ao controle da patologia, pode-se dizer que o controle da doença, neste caso, não é efetivo. Acredita-se que é necessário o próprio usuário elaborar esta questão.

As falas expõem as fragilidades e potencialidades que o encontro terapêutico tem ou pode ter. Parte das falas onde a percepção dos usuários era negativa foi levada para a roda de conversa. A reflexão foi instigada em relação à escuta qualificada do adoecido. Questionou-se sobre a abertura para ouvir o outro e em como esta atitude influencia a fala do outro. Os profissionais demonstraram certa autocrítica ao reconhecerem algumas situações que aconteceram em seu cotidiano, sendo apontando como maior dificultador da escuta a falta de tempo durante o atendimento e o volume de 
pessoas a serem atendidas no serviço. Relatam preocupação e empenho por melhorar os processos de saber-fazer e da necessidade de revisão de práticas instituídas no serviço.

Em suas falas, os profissionais reforçaram que a escuta é muito significativa para a sua prática clínica, partilharam estratégias pessoais para sua ampliação, desde a priorização dentro da consulta do que é urgente clinicamente, mantendo a escuta e solicitando um retorno mais breve; e em como o acesso às anotações e as percepções dos outros profissionais (prontuário eletrônico) tem permitido olhar o adoecido de uma maneira ampliada, valorizando as percepções de todos os profissionais da equipe.

As percepções singulares sobre o usuário, compartilhadas entre a equipe, podem potencializar o cuidado, como representado na seguinte fala:

"Sugiro você abrir mais espaço para o paciente falar, para você ter a tua percepção do paciente. Porque às vezes a percepção que a enfermeira tem é diferente da minha, ela interpreta uma coisa e eu interpreto bem outra. Não quer dizer que ela está certa ou eu estou certa... Às vezes a gente consegue lançar uma terceira estratégia, que a gente discutiu, que não é nem a minha estratégia inicial, nem a dela e surge uma terceira hipótese mesclando as coisas".

É importante ressaltar como a dimensão profissional deste encontro é singular, porque, nas falas, o vínculo formado entre as pessoas, profissionais e usuários é permeado pelas subjetividades e intersubjetividades, que tornam esse encontro único, em todos os momentos em que se abre espaço para que ele aconteça.

Quando questionados em relação ao insucesso terapêutico, a palavra mais frequente dos profissionais foi frustração, em relação ao usuário, mas, também, ao seu desempenho, associada a sentimentos como culpa por acreditar que não está realizando um bom trabalho, onde estão falhando e a impotência perante a situação.

$\mathrm{Na}$ roda de conversa, quando foi abordada a frustração como controle e responsabilização pelo paciente, enquanto parte do arcabouço que recebemos em nossa formação profissional, pela relação de poder "em que cada um procura dirigir a conduta do outro" ${ }^{26}$ (p. 3), houve incômodos no grupo. Uma fala torna-se representativa, pois pontua que a vivência profissional tem provocado mudanças no seu modo de saber-fazer, aprendendo a não se responsabilizar pelas atitudes do outro. Mas ainda demonstra inquietações, como a dificuldade em aceitar que o adoecido tem o seu tempo para fazer ou não as mudanças sugeridas.

A falta de negociação das medidas terapêuticas com o usuário pode ser um dos motivos da frustração, pois a responsabilidade acaba não sendo compartilhada. É necessário repensar a relação com o usuário e o processo de trabalho, pois a insatisfação vai provocando indiferença como uma forma de autoproteção, auxiliando na degradação da clínica.

Surgem falas relacionadas ao julgamento de valor pelos profissionais de saúde, em situações em que há incoerência entre a fala dos usuários e os resultados apresentados ou por não estarem abertos às mudanças.

No sucesso terapêutico, os afetos positivos se sobressaem enquanto satisfação pessoal, realização, alegria, apego, felicidade, reações de incentivo, congratulações e valorização dos resultados. As falas também demonstram que os profissionais se sentem parte desse sucesso, valorizando a conquista do usuário, o que corrobora para a motivação da equipe. Considera-se necessária a reflexão da equipe em relação à polaridade presente nas falas, onde os espaços coletivos de trocas podem ser uma das estratégias de intervenção.

Os profissionais conceituam bons resultados em relação ao tratamento, sempre na perspectiva do conhecimento biomédico, com amplitudes distintas e muito presentes as metas estabelecidas pelos profissionais médicos. Há uma fala em relação ao conhecimento a ser adquirido para que o usuário faça as suas escolhas com mais segurança, e outra em que, além da meta glicêmica ideal, seja valorizada a melhora apresentada. Em nenhuma das falas, há correlação com o questionamento aos usuários sobre o que são bons resultados para eles.

Sobre a segurança para lidar com os diabéticos, os profissionais de enfermagem que têm menos tempo de formação e vivência com o serviço especializado, relataram situações de insegurança, em 
relação ao conhecimento científico relacionado à patologia e sua percepção sobre as reações do adoecido.

$\mathrm{Na}$ roda de conversa, sobre as falas relacionadas ao poder existente entre profissionais e pacientes, houve a sinalização de momentos de insegurança em relação a extrapolar os limites da relação entre o médico e o usuário na interferência em sua vida pessoal e na responsabilidade profissional em não cometer erros.

Para haver a coconstrução do cuidado, a abertura dos profissionais de saúde em relação à opinião dos adoecidos ou de seus cuidadores no plano terapêutico é indispensável. Parte das falas dos profissionais de saúde admite ser essencial esta participação, outra pontua que a maioria dos adoecidos não negocia o tratamento e fala das estratégias que tenta utilizar para que haja participação; e outra que acredita que seja papel do médico a decisão sobre o tratamento.

Na roda de conversa, foi utilizada a expressão 'expectativas do paciente' para abordar a escuta qualificada, dos desejos e interesses significativos para o sujeito naquele momento da sua vida e da sua doença. Houve um momento de silêncio, sendo quebrado pela fala de uma das profissionais, onde refere esta tentativa de abordagem quando percebe que seu modo de fazer habitual não gerou resultados.

Outro profissional relatou uma situação em que a escuta levou à adaptação do esquema terapêutico inicialmente prescrito. Se fosse mantido o instituído, sem ouvir os interesses do adoecido, o cuidado não teria evoluído. A ampliação da escuta proporcionou a adequação do cuidado de uma maneira significativa para o usuário, onde a explicação e negociação de parte do esquema terapêutico resultaram na construção de compromissos entre os envolvidos e, inicialmente, com ganhos terapêuticos, pois houve a manutenção do acordado e melhora clínica.

Por meio desta narrativa, foi reforçada com os profissionais de saúde a possibilidade de ampliação dos resultados terapêuticos, por meio da negociação e pactuação das metas com os usuários e que os compromissos são mais importantes que as medidas de controle do outro.

As falas das pessoas com diabetes sobre possuir autonomia, em sua maioria, são afirmativas e relacionadas à capacidade de realização dos cuidados vinculados à doença, às atividades de vida diária e seus projetos de vida. Os motivos que foram considerados relevantes para exercê-la foram: o autoconhecimento, a motivação, a busca de informações, a necessidade de conhecer com o que está lidando, o aprendizado contínuo, a experiência, a capacidade de adaptação e o medo das complicações.

Nas falas em que a autonomia em relação à patologia ainda não está consolidada, os dificultadores apontados foram: a mudança de hábitos, as privações de alimentos, a insegurança, o esquecimento em relação aos cuidados como aplicação da insulina, a paciência com si mesmo, a consciência dos prejuízos que ela pode trazer para a vida e a mudança na alimentação.

Em relação a limitações/dependência percebidas, há falas em que a patologia não os limita em nada; outras citam o automonitoramento e a aplicação de insulina pela frequência de aplicação. No DM1, os jovens não consideram a possibilidade de dependência na vida deles. Ocorreram falas distintas em relação à alimentação, sendo uma cerceadora do desejo de se alimentar como quiser e na quantidade que quiser. A outra, que por meio dos cuidados alimentares decorrentes da diabetes, permitiu que ela controlasse sua vontade de comer sem controle. Surgiram falas sobre a diminuição do poder sobre si ao não poder dirigir um carro que não seja adaptado pelo uso da prótese e a aposentadoria precoce em virtude do risco de acidentes de trabalho pela hipoglicemia.

A autonomia aparece nas falas em graus variáveis, em como as pessoas lidam com sua rede de dependências de um modo singular, para poderem realizar seus projetos e tocar a sua vida apesar da doença. A fala de um dos entrevistados aborda a necessidade de deixar cada pessoa assumir as suas escolhas.

A percepção dos profissionais em relação ao conceito de autonomia está focada na independência, no poder de escolha, ter o controle sobre o que eu faço ou possuo, em não depender de outra pessoa para o seu autocuidado e nas suas atividades diárias.

Falas, enquanto autonomia vinculada a situações específicas de autocuidado ${ }^{27}$, são tranquilamente aceitas pelos profissionais de saúde. Porém, em relação às escolhas do plano terapêutico, a 
preocupação que transparece é se estas escolhas serão subsidiadas com informações consideradas seguras, como: o conhecimento científico, a consciência e a capacidade cognitiva. Uma das falas traz a heteronomia, considerando que os indivíduos têm dificuldades para manter o controle sem o outro. Com a discussão evoluindo em relação a ser mais do que a execução da prescrição dos profissionais de saúde, pois a vivência profissional sinaliza que as abordagens verticalizadas e uniformizadas não bastam para gerar resultados que impactam na vida das pessoas. Mas não é unânime.

A fala de uma das profissionais conceitua a autonomia vinculada ao conhecimento da pessoa sobre a doença, dominando os recursos terapêuticos disponíveis para aperfeiçoar seu uso, sendo o profissional de saúde apenas um apoiador em relação aos cuidados, e como responsável pela avaliação clínica "... é ele voar sozinho, conseguir gerenciar o seu tratamento, otimizando o que ele está fazendo...".

As disparidades nas falas entre os profissionais giram em torno da possibilidade de, gradativamente, ir ampliando a construção da autonomia do adoecido, conforme ele vai se apropriando dos cuidados. Por outro lado, mostra certo juízo de valor sobre a capacidade das pessoas de superarem suas limitações ou de fazerem suas próprias escolhas e construírem uma nova abordagem em que aquele cuidado seja singular.

$\mathrm{Na}$ análise entre as falas das pessoas com diabetes e dos profissionais de saúde, a vivência da autonomia pelos pacientes se apresenta de uma maneira muito mais leve do que as disposições teóricas dos profissionais, que podem estar vinculadas, consciente ou inconscientemente, ao receio dos profissionais em ter uma abordagem mais democrática com o adoecido.

$\mathrm{Na}$ Educação em Diabetes, o que é significativo para os adoecidos são grupos onde seja possível a troca de experiências e construção de saberes, pois eles têm interesse em aprender a lidar com as suas dificuldades em relação à patologia com a qual precisam conviver. Os profissionais de saúde ainda mantêm um discurso inicial focado em todos os conhecimentos biomédicos que são necessários para as pessoas aprenderem em relação à doença, mas, também, concordam com grupos menores, em que a troca de experiências e vivências tem um potencial maior de coconstrução. A busca de conhecimento pela internet é cada vez mais frequente entre profissionais e usuários.

\section{Conclusões}

Conforme este trabalho foi se desenvolvendo, tornaram-se mais claras a complexidade e a singularidade do processo de adoecer e vivenciar uma doença crônica; como é desafiador tanto para as pessoas que adoecem, como para os profissionais de saúde, lidar com a situação. Por outro lado, a certeza de que as abordagens biomédicas, pela redução da situação apenas sob um enfoque, não são suficientes para que as pessoas possam assumir o controle de suas vidas, apesar da doença.

O desafio é tornar a clínica de fato ampliada, transformando os modos de saber-fazer, sobretudo, enxergando o outro como um sujeito dotado de subjetividade, em que a escuta e a negociação de um plano terapêutico que faça sentido para o adoecido na sua vida, seja o objetivo do cuidado e da práxis, muito mais do que a adesão às recomendações dos profissionais de saúde, tornando a doença um dos aspectos da vida desta pessoa, não o principal.

O trabalho permitiu que a equipe vivenciasse um processo de mudança, ampliando a clínica e compartilhando, sobretudo com os outros profissionais da equipe, os vínculos e afetos, para melhoria do entrosamento entre a equipe e, em consequência, chegar à construção do cuidado com o usuário. Mas ainda é necessário lidar melhor com a máxima de que as escolhas são singulares, onde o papel do profissional é orientar e apoiar essas escolhas.

Acreditamos que seja necessário investir na coconstrução da autonomia da equipe e dos profissionais de saúde por meio da cogestão, para atingir a coconstrução da autonomia para as pessoas com diabetes, num efeito semelhante a círculos concêntricos em um lago, com mais intensidade em seu centro até atingir todo o campo a sua volta. 


\section{Colaboradores}

Rosilei Teresinha Weiss Baade participou da elaboração, execução, discussão e revisão da versão final do trabalho. Edison Bueno participou da discussão, revisão e da aprovação da versão final do trabalho.

\section{Referências}

1. Ministério da Saúde (BR). Secretaria de Vigilância em Saúde. VIGITEL Brasil 2013 Vigilância dos fatores de risco e proteção para doenças crônicas por inquérito telefônico [Internet]. 2013 [acesso 2014 Maio 5]. Disponível em: http://:www.portalsaude.saude. gov.br//portalsaude/.../vigitel_2013

2. International Diabetes Federation. IDF Atlas 5a ed 2012 update [Internet]. 2013 [acesso 2013 Dez 3]. Disponível em: http://www.idf.org

3. Oliveira JEP, Vencio S, organizadores. Diretrizes da Sociedade Brasileira de Diabetes: 2013-2014. São Paulo: AC Farmacêutica; 2014.

4. Grossi SSA, Pascali MP, organizadores. Cuidados de enfermagem em Diabetes Mellitus. Departamento de Enfermagem da Sociedade Brasileira de Diabetes. São Paulo: AC Farmacêutica; 2009.

5. Cyrino AP. Entre a ciência e a experiência: uma cartografia do autocuidado no diabetes. São Paulo: Ed. Unesp; 2009.

6. Campos GWS. Um método para análise e cogestão de coletivos: a constituição do sujeito, a produção de valor de uso e a democracia em instituições - o Método da Roda. São Paulo: Hucitec; 2000.

7. Dicionário on line em português [Internet] [acesso 2014 Dez 4]. Disponível em: http:// www.dicio.com.br

8. Campos GWS. Efeito Paidéia e o campo da saúde: reflexões sobre o sujeito, o mundo e a vida. Trab Educ Saude. 2006; 4(1):19-31.

9. Ferreira Neto $L$, Kind L, Pereira AB, Rezende MCC, Fernandes ML. Uso da noção de subjetividade na saúde coletiva. Cad Saude Publica. 2011; 27(5):831-42.

10. Michaelis. Moderno dicionário da língua portuguesa. São Paulo: Melhoramentos; 1998.

11. Marcondes HE, Japiassú D. Dicionário básico de filosofia [Internet]. 2008 [acesso 2013 Dez 3]. Disponível em: https://sbgdicionariodefilosofia/system/app/pages/ search?scope $=$ search-site $\& q=$ subjetividade

12. Crochick JL. Os desafios atuais do estudo da subjetividade na psicologia. [Internet]. Psicol USP. 1998; 9(2) [acesso 2014 Set 30]. Disponível em: http://dx.doi.org/10.1590/ S0103-65641998000200003

13. Tesser CD. A medicalização social (I): o excessivo sucesso do epistemicídio moderno na saúde. Interface (Botucatu). 2006; 10(19):61-76.

14. Campos GWS. Saúde Paidéia. 2a ed. São Paulo: Hucitec; 2003.

15. Cecílio LCO. A morte de Ivan Ilitch, de Loen Tóstoi: elementos para se pensar as múltiplas dimensões do cuidado. Interface (Botucatu). 2009; 13(1):545-55.

16. Merhy EE. Perda da dimensão cuidadora na produção da saúde: uma discussão do modelo assistencial e da intervenção no seu modo de trabalhar a assistência. Campinas; 1998.

17. Castellanos MEP, Barros NF, Motta JC. Resenha de Olhares socioantropológicos sobre os adoecidos crônicos. Cienc Saude Colet. 2008; 13 Supl 2:2309-11. 
18. Palmeira AT. Representações sociais de doença crônica: um estudo qualitativo com pessoas com diagnóstico de insuficiência renal ou dor crônica [dissertação]. Salvador (BA):Universidade Federal da Bahia; 2009.

19. Passos ICF. A construção da autonomia social e psíquica no pensamento de Cornelius Castoriadis. Pesqui Prat Psicos. 2006; 1(1):1-10.

20. Campos GWS, Onocko Campos RT. Coconstrução de autonomia: o sujeito em questão. In: Campos GWS, Minayo MCS, Bonfim JRA, Akerman M, Drumond Júnior M, Carvalho YM, organizadores. Tratado de Saúde Coletiva. 2a ed. São Paulo: Hucitec; 2012. p. 719-38.

21. Costa PP. Estudo do processo de coconstrução de conhecimento em um contexto de ensino fundamentado na modelagem [dissertação]. Belo Horinzonte (MG): Universidade Federal de Minas Gerais; 2012.

22. Minayo MCS. O desafio do conhecimento: pesquisa qualitativa em saúde. 14a ed. São Paulo: Hucitec; 2014.

23. Tavares BC, Barreto FA, Lodetti ML, Silva DMG, Lessmann JC. Resiliência de pessoas com diabetes mellitus. Texto Contexto Enferm. 2011; 20(4):751-7.

24. Boell JEW. Resiliência de pessoas com doenças crônicas: diabetes mellitus e doença renal crônica terminal [dissertação]. Florianópolis (SC): Universidade Federal de Santa Catarina; 2013.

25. Cavalcanti AM, Oliveira ACL, organizadores. Autocuidado apoiado: manual do profissional de saúde. Curitiba: Secretaria Municipal de Saúde; 2012.

26. Carvalho SR. Foucault: sobrevoo sobre a produção. Campinas: Unicamp; 2013. (Aula da disciplina de Gestão e Subjetividade, MPSC)

27. Silval J, Oliveira MFV, Silva SED, Polaro SHI, Radunz VR, Santos EKA, et al. Cuidado, autocuidado e cuidado de si: uma compreensão paradigmática para o cuidado de enfermagem. Rev Esc Enferm USP. 2009; 43(3):697-703.

Baade RTW, Bueno E. Co-construcción de la autonomía del cuidado de la persona con diabetes. Interface (Botucatu). 2016; 20(59):941-51.

Se trata de una investigación cualitativa sobre la co-construcción de la autonomía de la persona con diabetes por medio de las reflexiones de los usuarios diabéticos y profesionales de la salud de un equipo de una clínica pública especializada, ubicada en un municipio de tamaño medio en el sur de Brasil. Los datos fueron recolectados a través de entrevistas semiestructuradas a personas con diabetes, profesionales de la salud y una charla con profesionales sobre las narrativas de estos usuarios. El marco analítico de la presente investigación se basó en el análisis de contenido, específicamente el análisis temático. El acto de oír, la co-gestión y la clínica ampliada se colocaron como estrategias clave para entender y vivir con diabetes como un proceso singular que es posible alcanzar mediante la creación de estrategias compartidas entre los enfermos y los profesionales de salud, donde la enfermedad sea parte de la vida, y no la vida de la enfermedad.

Palabras clave: Co-construcción. Diabetes mellitus. Autonomía. Cuidado. Clínica ampliada.

Submetido em 11/03/15. Aprovado em 23/10/15. 
